MATEC Web of Conferences 40, 02025 (2016)

DOI: $10.1051 /$ matecconf/20164002025

(C) Owned by the authors, published by EDP Sciences, 2016

\title{
Stability Simulation of a Vehicle with Wheel Active Steering
}

\author{
Pavel Brabec, Robert Voženílek, Martin Lachman
}

Technical University of Liberec, Studentská 2, 46117 Liberec 1, Czech Republic

\begin{abstract}
This paper deals with the possibility of increasing the vehicle driving stability at a higher speed. One of the ways how to achieve higher stability is using the $4 \mathrm{WS}$ system. Mathematical description of vehicle general movement is a very complex task. For simulation, models which are aptly simplified are used. For the first approach, so-called single-truck vehicle model (often linear) is usually used. For the simulation, we have chosen to extend the model into a two-truck one, which includes the possibility to input more vehicle parameters. Considering the 4WS system, it is possible to use a number of potential regulations. In our simulation model, the regulation system with compound coupling was used. This type of regulation turns the rear wheels depending on the input parameters of the system (steering angle of the front wheels) and depending on the output moving quantities of the vehicle, most frequently the yaw rate. Criterion for compensation of lateral deflection centre of gravity angle is its zero value, or more precisely the zero value of its first-order derivative. Parameters and set-up of the simulation model were done in conjunction with the dSAPACE software. Reference performances of the vehicle simulation model were made through the defined manoeuvres. But the simulation results indicate that the rear-wheels steering can have a positive effect on the vehicle movement stability, especially when changing the driving direction at high speed.
\end{abstract}

\section{Introduction}

At the end of the last century, the designers seriously dealt with the idea how to increase the stability and adroitness (manoeuvrability) of passenger and utility vehicles. Some manufacturers offered vehicles with steered rear axle. The wheel-steering was both passive (elastokinematics) - rear-wheel deflection was initiated by force impacts when driving a car round a bend - and active. Active steering of the rear axle made it possible to control the vehicle better both at a low speed and manoeuvring in a limited area (parking etc.) and when changing the driving direction at a high speed. Active systems (named 4WS - Four-wheel Steering) are technically quite expensive. Rear wheels must be pivoted so that they can swivel and necessary conditions must be provided for that swivelling. Two aims are meant by installing the active wheels steering of the rear axle. Not only improving the adroitness when driving slowly, but also improving the stability when driving at a high speed [1], [2].

Rear-wheels deflection controlling is usually done according to the steering wheel rotation, but in two phases, which are selected with respect to the vehicle speed. The first phase is related to travelling at a low speed. In this phase, the rear wheels are rotated against the direction of rotation of front axle wheels; turning radius reduction occurs - movement pole approaches the vehicle and the vehicle movement trajectory can be curved more.

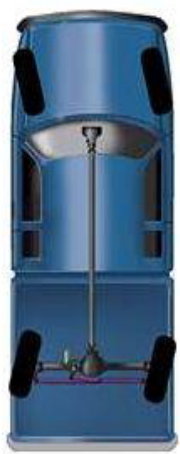

a)

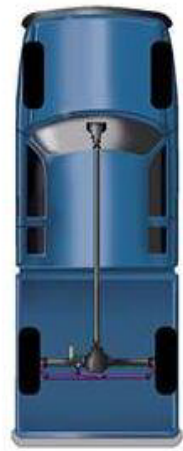

b)

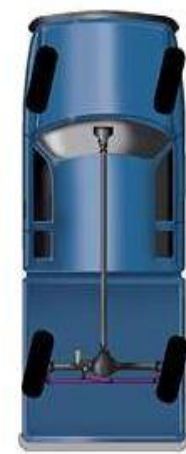

c)
Figure 1. Ways of rear wheels steering a) disconcordant steering, for moving at a very low speed, help when parking the car (approximately to $40 \mathrm{~km} / \mathrm{h}$ ); b) conventional steering, rear suspension wheels do not deflect; c) concordant steering, for increasing the stability when driving fast (source: GM DELPHI QUADRASTEER) [3].

The second phase is related to travelling at a high speed and the rear wheels are rotated in the same direction of rotation as the front axle wheels; turning radius growth occurs; however, at the same time the whole vehicle deviates from the original track [4]. 


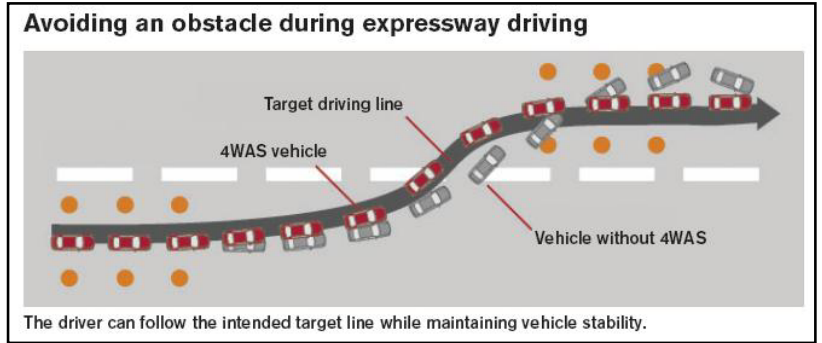

Figure 2. Comparison of a $2 \mathrm{WS}$ and a $4 \mathrm{WS}$ vehicle avoiding manoeuvre at a high speed. (Source: NISSAN Infiniti G37). [5]

\section{Simulation model description - a linear 3D model of a vehicle with four- wheel drive}

Mathematical description of vehicle general movement is a very complex task. For simulation, models which are aptly simplified are used. For the first approach, so-called single-truck vehicle model (often linear) [2] is usually used. For the simulation, we have chosen to extend the model into a two-truck one, which includes the possibility to input more vehicle parameters.

In the Fig. 3, there is a substitute linearised 3D vehicle model and it is possible to see the position of the vehicle coordinate system $x, y, z$ and the position and purpose of the vehicle yaw angle $\varepsilon$ and the position and purpose of vehicle slip angle $\alpha$. The whole vehicle centre of gravity $T$ lies in the height $h$ above the roadway and in the side view it is remote about the values $l_{p}$ and $l_{z}$ from axles. A bodywork can be tilted around the instant pitch axis connected tight to the vehicle. This axis is horizontal and goes in the vertical distance $h_{\psi}$ from the centre of gravity. Both wheels of the same axle can be - owing to external force or tilting - deflected about the same steering angle $\beta$ eventually about the same wheel camber angle $\xi$. As external force is illustrated lateral force from axle lateral deflection $S_{\alpha}$ and lateral force from wheel camber $S_{\xi}$ whose centre is distant from the wheel contact with the roadway by pneumatic caster $n_{\alpha}$ eventually by axle pin rearward rake $n_{\xi}$.

In the Fig. 4, there is also an alternative model of a steering system. Front wheels are turned around the steering swivel pins $0-0$. These are joint together using control levers in length $l_{\check{r}}$ and a one-piece steering connecting rod in a way that the both front wheels are turned about the same steering angle $\beta_{p}$. Steering knuckles have a design caster $n_{K}$ and a kingpin offset $r_{0}$. The steering mechanism is set in motion by the main steering arm which has the same length $l_{\breve{r}}$ as control levers. Therefore the steering-connecting-rod gearing is equal to one, and the overall steering ratio $i_{\check{r}}$ is given by steering-gear ratio.

The main steering arm performs the (slewing) angle motion $\beta_{V} / i_{\check{r}}$ with the damping factor which is proportional to the speed. The connection between the roll angle $\psi$ and front-wheel steering $\beta_{p}$, which, in practice, can be achieved by the choice of the axle kinematics and steering, is in the following figure replaced with the lever $C$.

This lever causes the steering $\beta_{p}$ extension (in positive meaning) if the bodywork is tilted in the positive direction. Just the same way as the whole vehicle model, even here operates the lateral force from the lateral deflections and from the wheels camber.

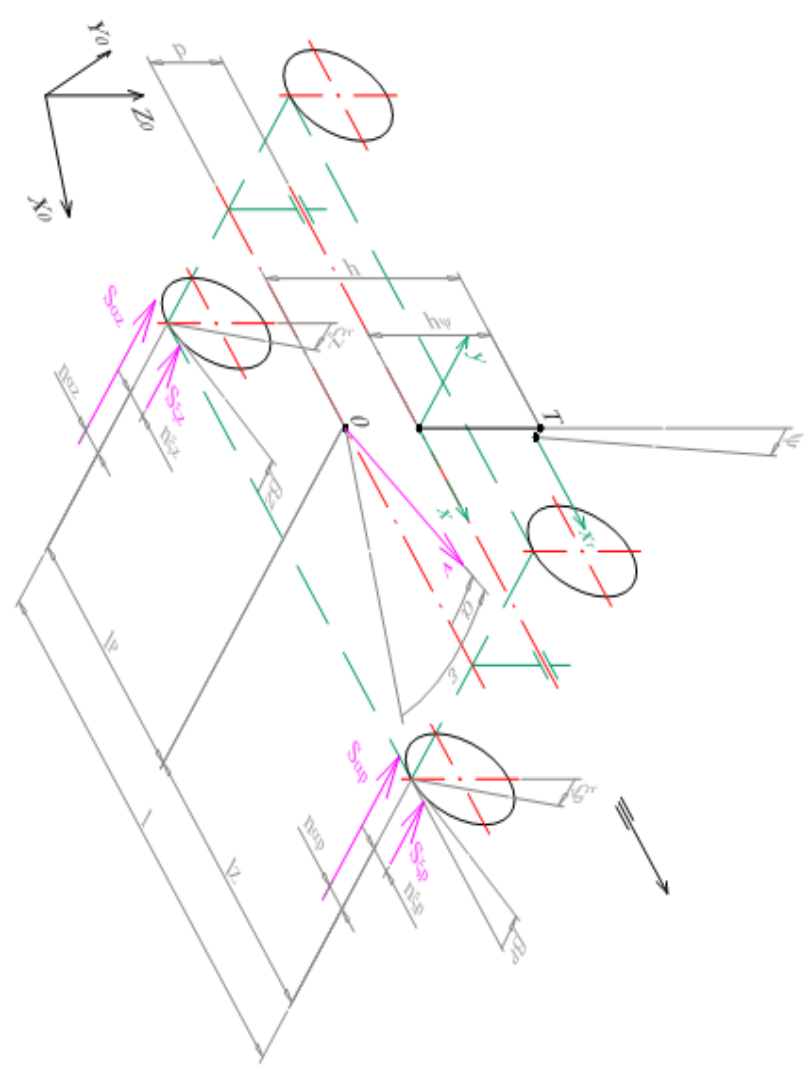

Figure 3. Simple 3D model of a vehicle.

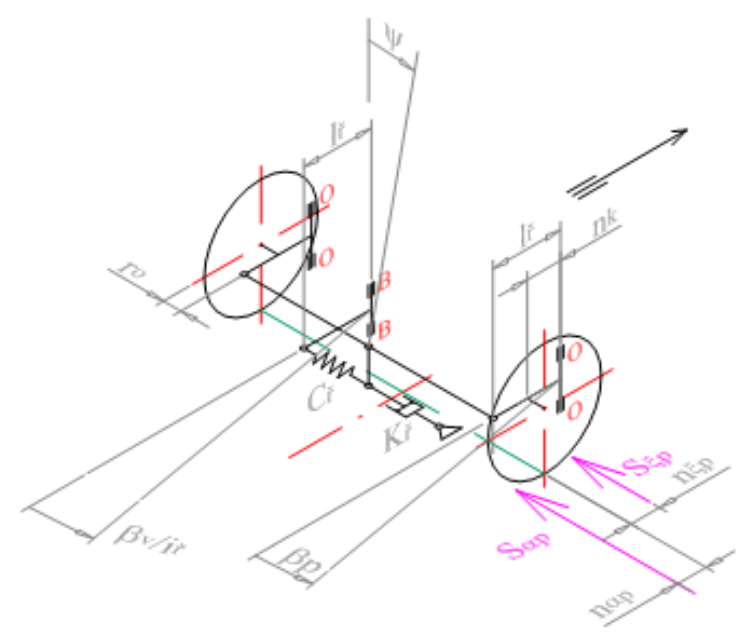

Figure 4. The spare model of a control mechanism.

Equations of motion for the spatial model car: balance of forces in the $y$-direction $-\mathrm{m} \cdot \mathrm{v} \cdot(\dot{\varepsilon}+\dot{\alpha})+\mathrm{m}_{\psi} \cdot \mathrm{h}_{\psi} \cdot \ddot{\psi}+\mathrm{S}_{\alpha \mathrm{p}}+\mathrm{S}_{\alpha \mathrm{z}}+\mathrm{S}_{\xi \mathrm{p}}+\mathrm{S}_{\xi \mathrm{z}}=0$

balance of moments about the $z$-axis 
$-\mathrm{J}_{\mathrm{z}} \cdot \ddot{\boldsymbol{\varepsilon}}+\left(\mathrm{l}_{\mathrm{p}}-\mathrm{n}_{\alpha \mathrm{p}}\right) \cdot \mathrm{S}_{\alpha \mathrm{p}}-\left(\mathrm{l}_{\mathrm{z}}+\mathrm{n}_{\alpha \mathrm{z}}\right) \cdot \mathrm{S}_{\alpha \mathrm{z}}+\left(\mathrm{l}_{\mathrm{p}}+\mathrm{n}_{\xi \mathrm{p}}\right) \cdot \mathrm{S}_{\xi \mathrm{p}}$

$-\left(\mathrm{l}_{z}-\mathrm{n}_{\xi z}\right) \cdot \mathrm{S}_{\xi \mathrm{z}}+\sum \mathrm{M}_{\mathrm{gz}}=0$

balance of moments about the $x_{T}$-axis

$-\mathrm{J}_{\psi} \cdot \ddot{\psi}-\mathrm{K}_{\psi} \cdot \dot{\psi}-\mathrm{C}_{\psi} \cdot \psi+\mathrm{G}_{\psi} \cdot \mathrm{h}_{\psi} \cdot \psi+\mathrm{h} \cdot \mathrm{S}_{\alpha \mathrm{p}}+\mathrm{h} \cdot \mathrm{S}_{\alpha z}$

$+\mathrm{h} \cdot \mathrm{S}_{\xi \mathrm{p}}+\mathrm{h} \cdot \mathrm{S}_{\xi_{\mathrm{z}}}+\sum \mathrm{MGX}_{\mathrm{GX}}=0$

balance of moments with respect to axes steering swivel pins $0-0$ (front axle)

$-\mathrm{J}_{\mathrm{o}} \cdot\left(\ddot{\beta}_{\mathrm{p}}+\ddot{\varepsilon}\right)-\mathrm{C}_{\mathrm{in}} \cdot\left[\beta_{\mathrm{p}}-\frac{\beta_{\mathrm{v}}}{\dot{\mathrm{I}}_{\mathrm{p}}}-\left(\frac{\partial \beta}{\partial \psi}\right)_{p} \psi \psi\right]-\mathrm{K}_{\mathrm{ip}} \cdot\left[\dot{\beta}_{\mathrm{p}}-\left(\frac{\partial \beta}{\partial \psi}\right)_{p} \dot{\psi}\right]$

$-\left(\mathrm{n}_{\mathrm{kp}}+\mathrm{n}_{\alpha_{\mathrm{p}}}\right) \cdot \mathrm{S}_{\alpha_{\mathrm{p}}}-\left(\mathrm{n}_{\mathrm{kp}}+\mathrm{n}_{\xi \mathrm{p}}\right) \cdot \mathrm{S}_{\xi \mathrm{p}}+2 \cdot \mathrm{M}_{\mathrm{G} \mathrm{p}_{\mathrm{p}}}=0$

balance of moments with respect to axes steering swivel pins $0-0$ (rear axle)

$-\mathrm{J}_{\mathrm{o}} \cdot\left(\ddot{\beta}_{\mathrm{z}}+\ddot{\varepsilon}\right)-\mathrm{C}_{\mathrm{zz}} \cdot\left[\beta_{\mathrm{z}}-\frac{\beta_{\mathrm{v}}}{\mathrm{i}_{\mathrm{z} z}}-\left(\frac{\partial \beta}{\partial \psi}\right), \psi\right]-\mathrm{K}_{\mathrm{iz}} \cdot\left[\dot{\beta}_{\mathrm{z}}-\left(\frac{\partial \beta}{\partial \psi}\right), \dot{\psi}\right]$

$-\left(\mathrm{n}_{\mathrm{kz}}+\mathrm{n}_{\alpha_{z}}\right) \cdot \mathrm{S}_{\alpha_{z}}-\left(\mathrm{n}_{\mathrm{kz}}+\mathrm{n}_{\xi_{z}}\right) \cdot \mathrm{S}_{\xi_{z}}+2 \cdot \mathrm{M}_{\mathrm{GZz}}=0$

Lateral forces from the directional deviations of the front and rear axle are described relationships

$$
\begin{aligned}
& \mathrm{S}_{\alpha \mathrm{p}}+\frac{\mathrm{C}_{\alpha \mathrm{p}}}{\mathrm{V} \cdot \mathrm{C}_{\mathrm{sp}}} \cdot \dot{\mathrm{S}}_{\alpha \mathrm{p}}=\mathrm{C}_{\alpha \mathrm{p}} \cdot \alpha_{\mathrm{p}} \\
& \mathrm{S}_{\alpha \mathrm{z}}+\frac{\mathrm{C}_{\alpha \mathrm{z}}}{\mathrm{V} \cdot \mathrm{C}_{\mathrm{sz}}} \cdot \dot{\mathrm{S}}_{\alpha \mathrm{z}}=\mathrm{C}_{\alpha \mathrm{z}} \cdot \alpha_{\mathrm{z}}
\end{aligned}
$$

Lateral forces from the directional deviations of the front and rear axle are described relationships

$$
\begin{aligned}
& \mathrm{S}_{\xi \mathrm{p}}=-\mathrm{C}_{\xi \mathrm{p}} \cdot \xi_{\mathrm{p}} \\
& \mathrm{S}_{\xi \mathrm{p}}=-\mathrm{C}_{\xi \mathrm{p}} \cdot \xi_{\mathrm{p}}
\end{aligned}
$$

Directional angles deviations of the front and rear axle in size

$$
\begin{aligned}
& \alpha_{\mathrm{p}}=-\alpha-\frac{1 \mathrm{p}}{\mathrm{V}} \cdot \dot{\varepsilon}+\beta \mathrm{P} \\
& \alpha_{\mathrm{p}}=-\alpha-\frac{1 \mathrm{p}}{\mathrm{V}} \cdot \dot{\varepsilon}+\beta \mathrm{P}
\end{aligned}
$$

Camber angle is described by equations

$$
\begin{aligned}
& \xi_{\mathrm{p}}=\left(\frac{\partial \xi}{\partial \psi}\right)_{p} \cdot \psi \\
& \xi_{\mathrm{z}}=\left(\frac{\partial \xi}{\partial \psi}\right)_{z} \cdot \psi
\end{aligned}
$$

The wheel is tilting angular velocity $\dot{\xi}$ around the $\mathrm{x}$ axis, thereby forming a gyro torque. Positive change the camber causes gyroscopic moment, which reduces the angular rotation of the wheel

$$
\mathrm{M}_{\mathrm{GZ}}=-\mathrm{J}_{\mathrm{K}} \cdot \frac{\mathrm{v}}{\mathrm{r}_{\mathrm{d}}} \cdot\left(\frac{\partial \xi}{\partial \psi}\right)_{j} \cdot \dot{\psi}
$$

If rotates the wheel about its axis $z$, then, an additional gyroscopic torque

$$
\mathrm{M}_{\mathrm{GX}}=\mathrm{J}_{\mathrm{K}} \cdot \frac{\mathrm{v}}{\mathrm{r}_{\mathrm{d}}} \cdot\left(\dot{\varepsilon}+\dot{\beta}_{\mathrm{j}}\right)
$$

All these equations can be summarized to seven linear differential equations with these variables:

○ slip angle $\alpha$,

$\circ$ yaw rate $\varepsilon$, $\circ$ tilting angle $\psi$,

- lateral force from lateral deflection on the front suspension $S_{\alpha p}$,

- lateral force from lateral deflection on the rear suspension $S_{\beta p}$,

$\circ$ steering angle of the front wheels $\beta_{P}$,

$\circ$ steering angle of the rear wheels $\beta_{Z}$.

Arbitrary variable and excitation function of a vehicle system is the steering-wheel steering angle $\beta_{V}$.

\section{Rear-wheel steering with the compensation of lateral deflection centre of gravity angle}

Considering the 4WS system, it is possible to use a number of potential regulations. In our simulation model, the regulation system with compound coupling was used. This type of regulation turns the rear wheels depending on the input parameters of the system (steering angle of the front wheels) and depending on the output moving quantities of the vehicle, most frequently the yaw rate. Criterion for compensation of lateral deflection centre of gravity angle is its zero value, or more precisely the zero value of its first-order derivative $(\alpha=\dot{\alpha}=0$ and for the steady motion $\dot{\varepsilon}=$ konst., tzn. $\ddot{\varepsilon}=0$ ) [2].

After substituting these conditions into two linear equations of motion it is possible to deduce the theoretical dependence for the required steering angle of the rear wheels. This dependence between the steering angle of the front wheels and the driving speed as the input quantities, and the steering angle of the rear wheels as the output quantities, is for the section of medium and high speed (concordant steering). A flow diagram of regulation is illustrated in the following figure. [6]

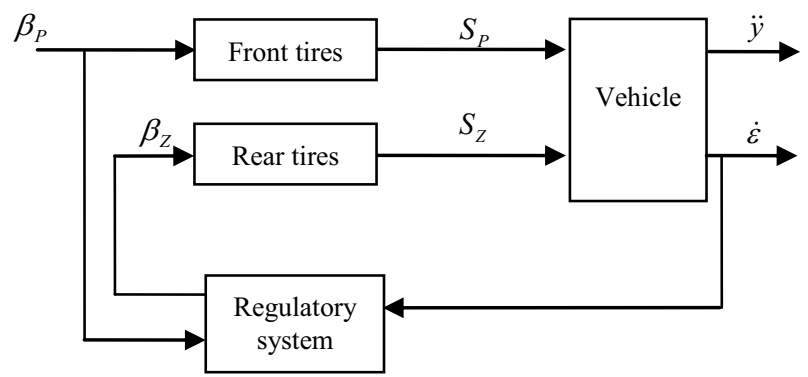

Figure 5. Flow diagram of regulation with compound coupling of 4WS system.

From the above described condition develops the dependence of turning the rear wheels on the vehicle speed and the front wheels turning. The Fig. 6 shows an illustration for a passenger vehicle of a standard size. The maximum rear wheels steer is further limited by adhesion and maximum value on account of a collision (size of the free space in the arch bodywork. 


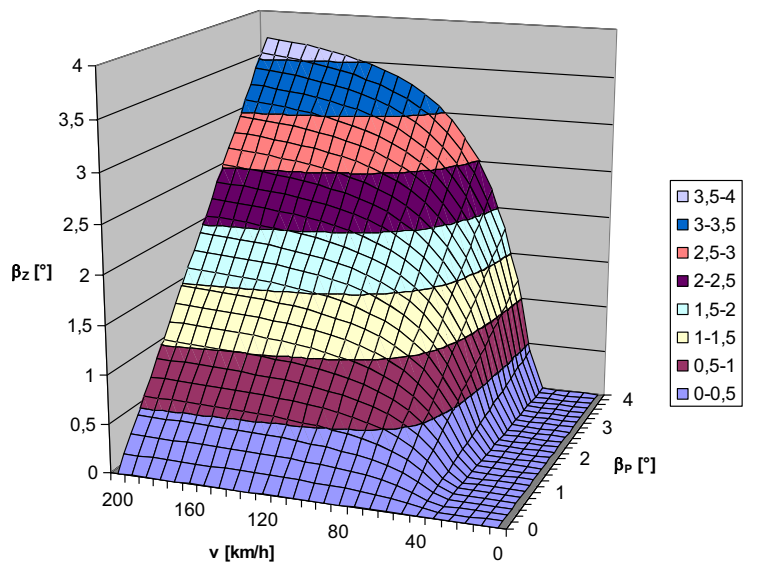

Figure 6. Theoretical characteristic for rear wheel steer of a passenger vehicle.

In the Fig. 7 we can see the results from the simulation and comparison of a car with conventional steering and with the 4WS system with the compensation of lateral deflection angle when doing the avoiding manoeuvre. Parameters and set-up of the simulation model were done in conjunction with the dSAPACE software. Reference performances of the vehicle simulation model were made through the defined manoeuvres. One of the typical manoeuvres is the vehicle get-through throughout a defined corridor specified in ISO 3888-2; you can see the results of these manoeuvres below.

Other arrangements of simulation models are dealt with within the frame of the Centres of Competence project, Project \# TE01020020 Josef Božek Competence Centre for Automotive Industry (this research has been realized using the support of Technological Agency, Czech Republic).

\section{Summary}

It is more sophisticated and expensive (compared to a traditional design) to create a chassis with steered rear axle. But the simulation results indicate that the rearwheels steering can have a positive effect on the vehicle movement stability, especially when changing the driving direction at high speed. The calculated ratio dependence of rear-wheels steering to front-wheels steering is still necessary to optimise during some driving tests. Obtaining the necessary input data for simulation model is very demanding and require a large number of measured values and experience. Simulation models, however, provide easy access to the verification of possible regulatory dependencies that after tuning to a eal vehicle can contribute to increased safety. The range at the high speeds and big front-wheel steering is limited by the lateral stability.
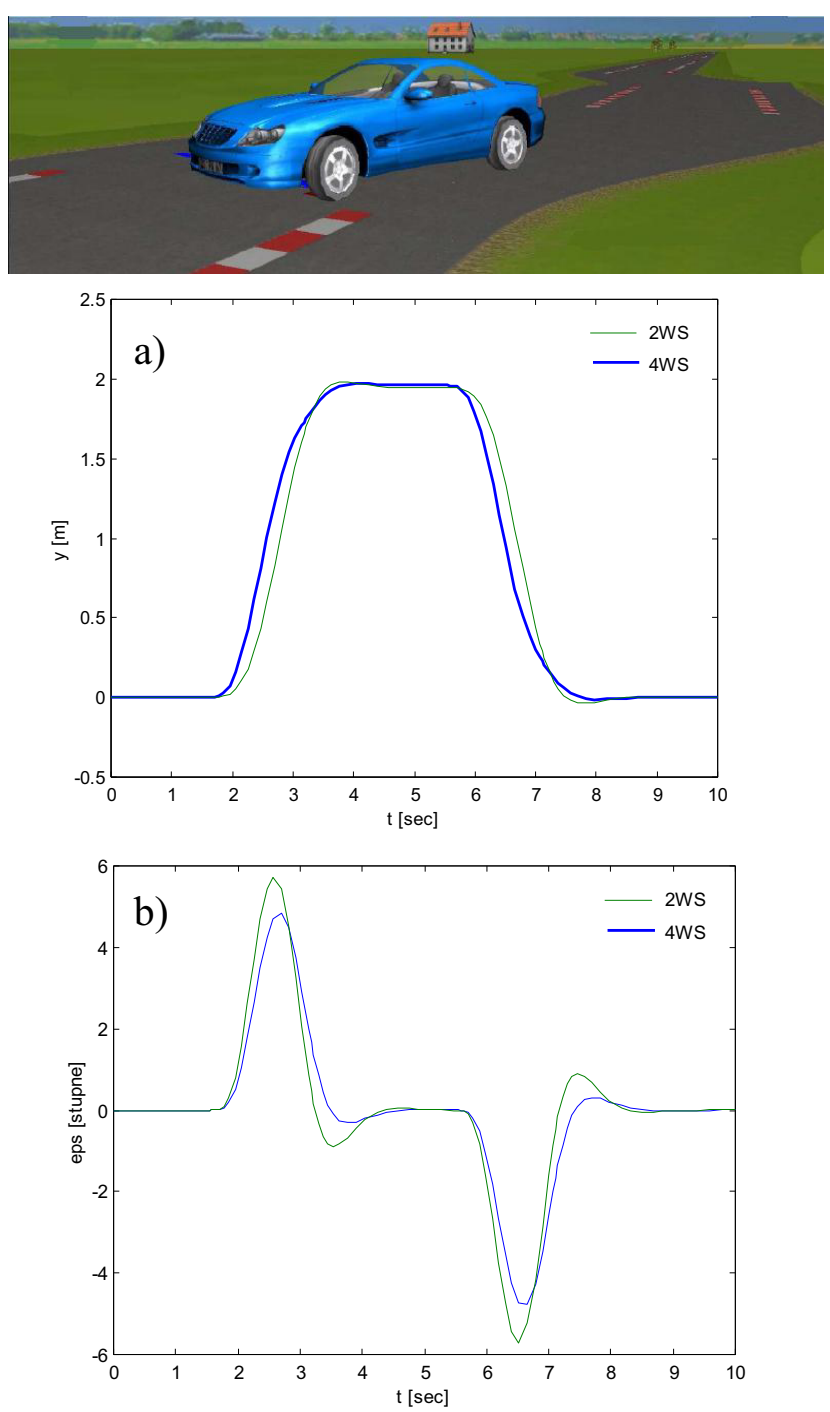

Figure 7. Simulation results for comparing a vehicle with conventional steering and with 4WS system with compensation of lateral deflection angle during a defined manoeuvre: a) lateral breakaway in the transverse direction, b) yaw angle.

\section{References}

1. F. VLK, Motor-powered vehicle chassis, VLK, Brno (2000)

2. F. VLK, Motor-powered vehicle conception, VLK, Brno (2000)

3. Information on http://www.pickuptrucks.com/html/2004/chevrolet/si lverado/page1.html

4. HONDA, E-4WS Construction and Function (Based on the 1997 Prelude), service manual (1997)

5. Information on http://www.nissanglobal.com/EN/DOCUMENT/PDF/TECHNOLOGY /TECHNICAL/4was_en.pdf

6. F. ZAPLETAL, Increasing the active safety of vehicles using the 4WS and AFWS system, dissertation work, Brno (1997) 